\title{
The Preliminary Study for Postoperative Radiotherapy Survival Associated with RUNX3 and TLR9 Expression in Lung Cancer
}

\section{Caixia Gao \\ Tiankui Qiao (D) \\ Sujuan Yuan \\ Xibing Zhuang (D)}

Jinshan Hospital Center for Tumor Diagnosis \& Therapy, Shanghai, 201508,

People's Republic of China
Correspondence: Tiankui Qiao Jinshan Hospital of Fudan University, No. 1508 Longhang Road, Jinshan District, Shanghai, 201508, People's Republic of China

Tel +86 I8930778786

Email qiaotk@163.com
Background: Many studies have reported that the inflammatory immune response related to TLR9 signaling activation participates in tumor development and affects the treatment outcome. $R U N X 3$ functions as a tumor suppressor by regulating DNA methylation. RUNX3 protein plays an important role in TGF- $\beta$ signaling pathway that is involved in tumor growth inhibition and apoptosis. At present, radiotherapy is still an important treatment in lung cancer, which induces immune response and affects the therapeutic outcome. The role of TLR9 signaling activation and RUNX3 in this process is not clear.

Methods: In this study, we investigated the expression of TLR 9 in tumor and $R U N X 3$ in surrounding tissues by immunohistochemical methods and analyzed the relationship on postoperative survival in lung cancer.

Results: We found that the high expression of TLR 9 was the risk factor in postoperative survival of lung cancer with no difference in lifetime. The high expression of RUNX3 in lung cancer with TLR9 signaling activation was in favor of progression-free survival and overall survival in postoperative radiotherapy. It suggested that $R U N X 3$ played an important role in lung cancer radiotherapy. In order to determine the effect of $R U N X 3$ in lung cancer radiation with TLR9 signaling activation, we introduced 5-Aza-2'-deoxycytidine (5-Aza-CdR) and exposed lung cancer A459 cells repeatedly. The high expression of RUNX3 especially $R U N X 3-\mathrm{B}$ in cells treated with 5 -Aza-CdR was observed. We examined that 5 -Aza-CdR induced more cell blocking in $\mathrm{G} 2 / \mathrm{M}$ phase in combining irradiation.

Conclusion: The result implied that it was feasible to improve radiosensitivity of lung cancer with TLR9 signaling activation by increasing RUNX3 expression, and 5-Aza-CdR was an option in this process.

Keywords: TLR 9 signaling activation, $R U N X 3$ expression, 5-Aza-CdR, radiotherapy, lung cancer

\section{Introduction}

Although radiotherapy is one of the most effective treatments for non-small-cell lung carcinoma, local recurrence and metastasis are the main reasons for the failure of clinical treatment. There is an urgent need to explore the relationship of radiotherapy and tumor development for lung cancer treatment currently.

$T L R 9$ is a member of toll-like receptor family, binding DNA in bacteria and viruses. TLR 9 is a pattern recognition receptor connecting innate and adaptive immune systems. ${ }^{1}$ The researchers have demonstrated that TLR9 is expressed in multiple cancer cells. $^{2}$ The signaling activation causing inflammatory cytokine response such as TNFa, 
IL-1, IL-6, IL-8 promotes tumor proliferation and microenvironment development, contributing to a huge impact on clinical tumor treatment. ${ }^{3,4}$ Ren et al reported that the activation of TLR9 signal in lung cancer cells upregulated inflammatory cytokines, MMP-2, chemokines, and immunosuppressive factor (IL-10) levels, leading to significant enhancement of tumor proliferation, invasion and metastasis. ${ }^{5,6} \mathrm{CpG}$-oligodeoxynucleotide induced TLR9 activation increasing prostate cancer metastasis has been confirmed. ${ }^{7}$ And the correlation of TLR 9 high expression and poor tumor grading or later tumor staging had been reported in prostate cancer, glioma and esophagus tumor. $^{8-10}$ RUNX3 is a protein-coding gene that functions as a tumor suppressor and regulates cell development, apoptosis, signaling transduction, etc. ${ }^{11,12}$ Recently it was reported that $R U N X 3$ has a regulatory function on tumor immunity, whose upregulation can facilitate the expression of T-bet and promote Th1 immune response. ${ }^{13-15}$ Irradiation triggering signaling cascade and leading to upregulation of more than 60 genes involved in cell cycle regulation, DNA damage and repair, apoptosis, oncogenes and tumor suppressor genes, cell metabolism, etc have reported. ${ }^{16}$ And how TLR9 signal activation and RUNX3 expression influence radiotherapy outcome have rarely been reported. In this study, we surveyed the effect of TLR 9 in tumor tissues and $R U N X 3$ in adjacent carcinoma tissues on postoperative radiotherapy survival in lung cancer. 5-Aza-2'deoxycytidine (5-Aza-CdR) is one of the inhibitors of DNA methyltransferase. Studies have shown that epigenetic changes of DNA methylation and histone modification affect tumor development and treatment. ${ }^{17}$ It is believed that DNA methyltransferase could inhibit transcription of target genes by forming transcription repressors with histone methyltransferase at promoter region. ${ }^{18}$ The application of 5-Aza$\mathrm{CdR}$ and the analog 5-azacitidine in tumor chemoradiotherapy has been reviewed. ${ }^{19,20}$ We had determined the radiation resistance in lung cancer A549 cells exposed repeatedly in preliminary study, which TLR 9 expression upregulated. ${ }^{21}$ In the study we would investigate the role of RUNX3 in 5-AzaCdR combined radiotherapy for cells with TLR 9 signal activation and further elucidated that it was significant in raising $R U N X 3$ expression for lung cancer radiotherapy.

\section{Materials and Methods}

\section{Clinical Information Related to the Cases}

Sixty-three patients were enrolled in the study for tumor resection and postoperative chemoradiotherapy in JinShan
Hospital of Fudan University from March 1, 2010 to December 31, 2011. Fifty-two males and 11 females were selected. The oldest patient was 76 years old, and the youngest was 36 years old. The median age was 63 years. Forty-two cases had a smoking history. All patients received a preoperative pathological diagnosis. Sixty-one patients accepted lobectomy and lymph node dissection while two patients took unilateral pneumonectomy. Thirtysix squamous carcinomas apart from three sarcomatoid carcinomas and 27 adenocarcinomas, including three adeno-squamous carcinomas were diagnosed pathologically after tumor resection. There were 28 cases of mediastinal lymph node metastasis. The postoperative tumor tissues of 63 patients were selected as the effective specimens for this experiment. This was conducted in accordance with the Declaration of Helsinki. The study was approved by the Ethics Committee of Jinshan Hospital, Fudan University (Shanghai, China), together with the confirmation that all patients whose tissue was used provided written informed consent.

Thirty-six patients received radiotherapy within three months postoperatively. The conditions for postoperative radiotherapy were as follows: positive edge-cutting and/or mediastinal lymph node metastasis, KPS score $\geq 85$ and FEV 1.0 of pulmonary function $\geq 80 \%$. The signature confirmation for postoperative radiotherapy was signed. Intensity-modulated radiation therapy (IMRT) was adopted for postoperative radiotherapy. The target drawings referred to the NCCN non-small-cell lung cancer clinical practice guidelines. Clinical target volume (CTV) put on $5-8 \mathrm{~mm}$ externally as the planning target area (PTV). Ninety-five percent isodose line covering the $100 \%$ volume of PTV was approved. The dose limits of dangerous organs was as follows: the side lung V30 $\leq 25 \%$, total lung V20 $\leq 25 \%$, mean dose of the side lung $\leq 18 \mathrm{~Gy}$, heart maximum dose $\leq 45$ Gy, spinal cord $\leq 45$ Gy. The plan was administrated by $6 \mathrm{MV} \mathrm{X}$-ray for the total dose $50 \mathrm{~Gy} / 25 \mathrm{Fx}$, adding up to 56-60 Gy/28-30 Fx for the patient's positive surgical margin. Thirty-six patients completed postoperative radiotherapy with no serious side effects.

The follow-up began three months after surgical treatment and/or chemoradiotherapy and ended in February 2015. It was once every three months for two years and every six months for two years. The median for follow-up was 38 months. The time from the first visit to tumor recurrence was determined as progressive-free survival (PFS). The time from the visit ending or death 
in follow-up was defined as overall survival (OS). Fortyeight patients died of lung cancer and one non-neoplastic death. Twelve patients were alive except for four survival with tumor recurrence and two lost. The ratio of follow-up was $96.8 \%$. The outpatient booking for follow-up was preferred, letter or telephone visit as a supplement.

\section{Expression of TLR9 and RUNX3 in Cancer Tissues}

The wax blocks of lung cancer tissues were cut into sections of $4 \mu \mathrm{m}$, fixed and labeled. After being deparaffinized, hydrated and antigen retrieval, the sections were treated with $3 \%$ hydrogen peroxide and 1\% FBS. Diluted primary antibody (Rabbit Anti-TLR9 polyclonal antibody 1:1000 and Rabbit Anti-RUNX3 monoclonal antibody 1:1000, Abcam, US) was added and incubated at $4{ }^{\circ} \mathrm{C}$ overnight. HRP-Polymer Antimouse Immunohis tochemistry (IHC) Kit (KIT-5930 Maixin Biology, Fuzhou, China) was incubated for $30 \mathrm{~min}$ at room temperature, followed by diaminobenzidine for color development. Finally the sections were counterstained with hematoxylin and mounted with Permount. The scores were determined by the proportion of stained cells and intensity. The cells binding TLR 9 protein in tumor tissues and $R U N X 3$ protein in paracarcinoma tissues was counted respectively. The proportion of stained cells was graded as follows: 0 (no stained cells), 1 (10\% stained cells), 2 (10-50\% stained cells) and 3 (50\% stained cells). The intensity of the stain was recorded on a scale of 0 (no staining), 1 (weak staining, light yellow), 2 (moderate staining, yellowish brown) and 3 (strong staining, brown). The staining index was calculated as follows: staining index $=$ staining intensity + score of stained cells. Tissue sections with staining index over 4 were defined as high expression and staining index less than 4 as low expression.

\section{Preparation for Lung Cancer A549 Cell with TLR9 Signal Activation and the Experimental Groups}

Human lung cancer A549 cell line from Shanghai Tumor Hospital, Fudan University (Shanghai, People's Republic of China) was approved by the Ethics Committee of Jinshan Hospital, which was used for the preparation of the target cell line based on our previous study. A549 cell in logarithmic growth was exposed $6 \mathrm{MV}$ X-ray, source to surface distance $(\mathrm{SSD}=100 \mathrm{~cm})$ irradiation with dose rate
2 Gy/min and once 6.37 Gy for 10 exposures. $^{21}$ The irradiation was performed once again until 63.7 Gy. And this cell line was designated as lung cancer A549 cell with high-TLR9 expression (A549 ${ }^{\text {high-TLR9 }}$ ). 5-Aza-CdR (Merck Drugs \& Biotechnology, Sigma-Aldrich, Germany) was prepared for experimental cells in $0.5,1.0,2.0,5.0$ and $10 \mu \mathrm{mol} / \mathrm{L}$, respectively. The absorbance was measured by microplate spectrophotometer at $450 \mathrm{~nm}$. According the measurement, $5.0 \mu \mathrm{mol} / \mathrm{L}$ 5-Aza-CdR and $10 \mu \mathrm{g} / \mathrm{mL}$ chloroquine (CQ) were adopted for the treatment in experimental cells.

The cells were divided into six groups: A549 group, A549 $9^{\text {high-TLR9 }}$ group, A549 $9^{\text {high-TLR9 }} /$ IR (cell irradiation) group, A549 ${ }^{\text {high-TLR9 }}+\mathrm{CQ} / \mathrm{IR}$ (chloroquine combining irradiation) group, A549 ${ }^{\text {high-TLR9 }}+5$-Aza-CdR/IR (5-Aza-CdR combining irradiation) group, A549 ${ }^{\text {high- } T L R 9}+5-\mathrm{Aza}-\mathrm{CdR}$ (5-Aza-CdR treatment) group. The cells were administrated in serum-free medium with $10 \mu \mathrm{g} / \mathrm{mL}$ chloroquine and 5 $\mu \mathrm{mol} / \mathrm{L}$ 5-Aza-CdR respectively before IR $30 \mathrm{~min}$.

\section{Detection of TLR9 and RUNX3 Protein by Western blotting}

After cell disruption and centrifugation, protein extracts concentration were determined by the BCA method and separated by $10 \%$ SDS-PAGE, transferred to polyvinylidene difluoride (PVDF) membranes (EMD Millipore, Billerica, MA, USA). The membrane was blocked with $10 \%$ nonfat dry milk in Tris-buffered saline (TBS) containing $0.1 \%$ Tween-20 (TBS-T) for $2.5 \mathrm{~h}$ at room temperature and then incubated with the following primary antibodies at $4{ }^{\circ} \mathrm{C}$ overnight: Rabbit TLR9 monoclonal antibody 1:5000 (Abcam, USA), Rabbit RUNX3 monoclonal antibody 1:1000 (Abcam), Mouse GAPDH monoclonal antibody 1:3500 (Proteintech, USA). Membranes were washed with TBS-T three times and probed with secondary antibodies for two hours at room temperature. Protein bands were visualized after incubation with chemiluminescence HRP substrate (EMD Millipore).

\section{Cycle Distribution of Cells in Experimental Groups}

The cells were exposed with $6 \mathrm{MV} \mathrm{X}$-ray, a single dose of 10 Gy. The cell culture was replaced once after irradiation 24 h. The cells irradiated $0 \mathrm{~h}, 12 \mathrm{~h}, 24 \mathrm{~h}, 36 \mathrm{~h}, 48 \mathrm{~h}$ were harvested and fixed with $75 \%$ ethanol at $4{ }^{\circ} \mathrm{C}$ overnight, then incubated with $500 \mu \mathrm{L}$ propidium iodide/RNase staining buffer (BD Biosciences) at room temperature for $15 \mathrm{~min}$. After 
centrifugation and PBS washing, the cell cycle reagent PI $(50 \mathrm{mg} / \mathrm{mL})$ was added to suspended cells avoiding light at $4^{\circ} \mathrm{C}$ for $20 \mathrm{~min}$. The cell cycle was determined by flow cytometer.

\section{Statistical Analysis}

SPSS 17.0 statistical software (SPSS, Inc., Chicago, IL, USA) was used in the study. The one-way variance analysis of $T L R 9$ and $R U N X 3$ and clinicopathological features was tested by chi-squared test. The risk assessment of factors on postoperative survival of lung cancer was measured by logistic regression. The prediction of factors associated on postoperative radiotherapy survival was examined by Cox regression. The life tables were used for calculating the survival time related to TLR 9 and $R U N X 3$. The measurement data showed on $\mathrm{x} \pm \mathrm{s}$ and analysis of variance was adopted in comparison of the groups. The statistical figures were made by GraphPad Prism 5.0 software. $P<0.05$ was regarded as statistically significant.

\section{Results}

\section{The Relationship of TLR9 and RUNX3 and Postoperative Radiotherapy Survival in Lung Cancer}

The expression of TLR9 in tumor tissues and RUNX3 adjacent to cancer was shown in Figure 1. Forty-three and 28 of 63 patients presented positive expression of $T L R 9$ and $R U N X 3$ respectively. The relationship of TLR 9 and $R U N X 3$ and clinicopathological characteristics by one- way variance analysis was presented in Table 1 . The results displayed that the high expression of TLR 9 in cancer tissues emerged in later $\mathrm{T}$ stage significantly $\left(\chi^{2}=8.620, \quad P=0.013\right)$, which the high expression of $R U N X 3$ in paracarcinoma tissues was likely to in earlier T stage $\left(\chi^{2}=5.920, P=0.052\right)$. RUNX3 expression in nonsquamous carcinoma showed statistic difference, the chisquared value being 4.200 and $P=0.040$. The expression of $T L R 9$ and RUNX3 in tumor differentiation, $\mathrm{N}$ staging, and postoperative radiotherapy had no distinction.

Then we conducted the risk assessment on TLR9, $R U N X 3$ and above clinical features for postoperative survival in lung cancer by logistic regression, shown in Table 2 . The result revealed that the relative risk value associated with tumor $T$ staging and TLR 9 expression in the model was 2.716 and 5.057, respectively. It suggested that the high expression of TLR 9 was harmful for postoperative survival in lung cancer with the $P$-value 0.019 significant. The median time of PFS and OS associated with TLR9 expression was shown in Table 2, with no difference in postoperative or radiotherapy patients. The cumulative survival ratio on $T L R 9$ expression in postoperative or radiotherapy patients was exhibited in Figure 2. Subsequently the median survival time of PFS and OS in postoperative radiotherapy associated with TLR 9 and $R U N X 3$ expression was analyzed and shown in Table 3. The statistical value of PFS and OS in postoperative radiotherapy related $R U N X 3$ expression and negative $T L R 9$ was 1.905 and 4.224, respectively, $P=0.168$ and 0.040. With positive TLR9 it was 6.097 and 6.521, respectively, $P=0.014$ and 0.011 significantly, as shown in

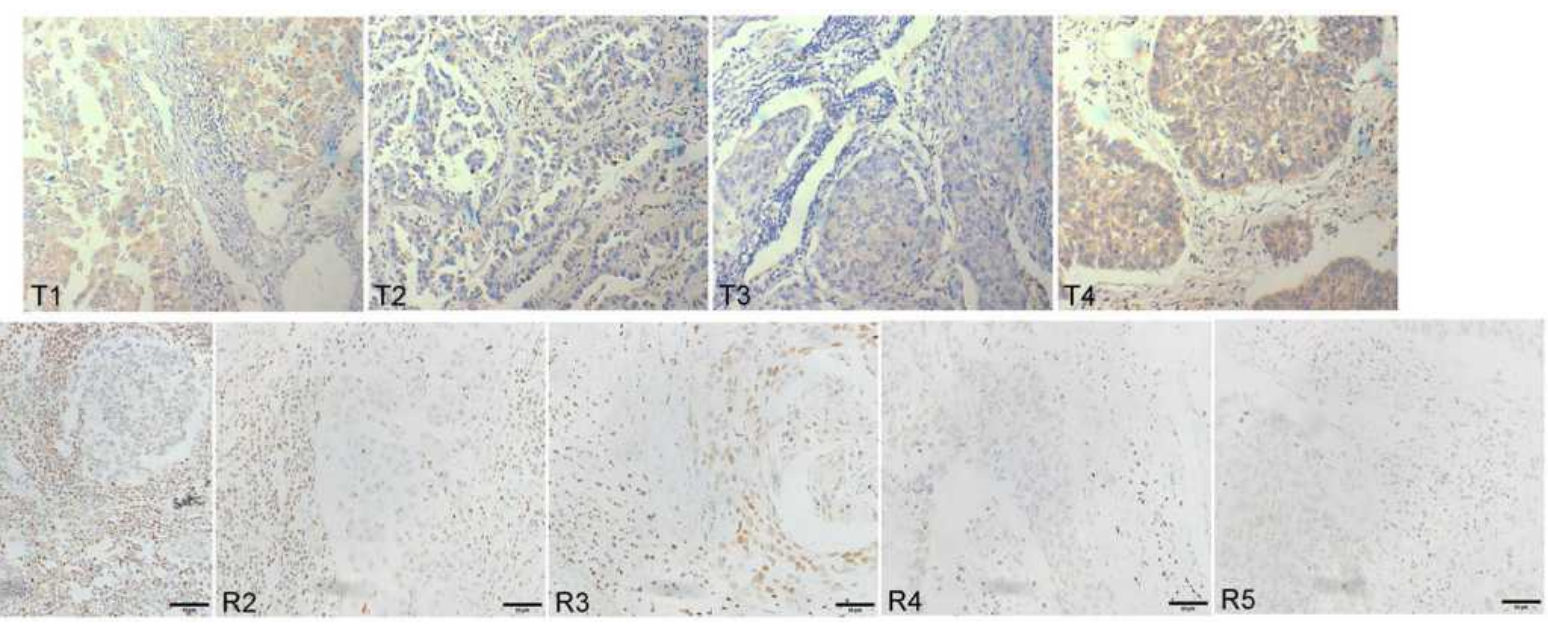

Figure I The expression of TLR9 and RUNX3 in lung cancer tissues (immunohistochemical SP method). Expression of TLR9 in tumor tissues (TI-T4) and RUNX3 in adjacent to cancer (RI-R5) was examined with DAB magnification $400 \dot{X}$. Compared with normal bronchoalveolar cells, tumor cells became larger in volume and abnormally clumped together. TLR9 protein stained yellow or brown distributed equality in cytoplasm of tumor cells with unusual karyomegaly, multileaf nuclear and nuclear membrane thickened, etc. RUNX3 protein stained yellow or brown granular distributed in nucleus. 
Table I The One-way Analysis of Variance on TLR9 and RUNX3 Expression in Lung Cancer Tissues

\begin{tabular}{|c|c|c|c|c|c|c|c|c|c|c|}
\hline & & \multirow[t]{2}{*}{$\mathbf{n}$} & \multicolumn{2}{|c|}{ TLR9 Expression } & \multirow[t]{2}{*}{$\chi^{2}$} & \multirow[t]{2}{*}{$\mathbf{P}$} & \multicolumn{2}{|c|}{ RUNX3 Expression } & \multirow[t]{2}{*}{$\chi^{2}$} & \multirow[t]{2}{*}{$\mathbf{P}$} \\
\hline & & & Low (\%) & High (\%) & & & Low (\%) & High (\%) & & \\
\hline Pathology & $\begin{array}{l}\text { Squamous carcinoma } \\
\text { Nonsquamous carcinoma }\end{array}$ & $\begin{array}{l}36 \\
27\end{array}$ & $\begin{array}{l}11(17.5) \\
9(14.3)\end{array}$ & $\begin{array}{l}25(39.7) \\
18(28.6)\end{array}$ & 0.055 & 0.815 & $\begin{array}{l}24(38.1) \\
11(17.5)\end{array}$ & $\begin{array}{l}12(19.0) \\
16(25.4)\end{array}$ & 4.200 & 0.040 \\
\hline Differentiation & $\begin{array}{l}\text { Highly } \\
\text { Moderately } \\
\text { Poorly }\end{array}$ & $\begin{array}{l}12 \\
30 \\
21\end{array}$ & $\begin{array}{l}5(7.9) \\
9(14.3) \\
6(9.5)\end{array}$ & $\begin{array}{l}7(11.1) \\
21(33.3) \\
15(23.8)\end{array}$ & 0.685 & 0.710 & $\begin{array}{l}10(15.9) \\
16(27.8) \\
9(14.3)\end{array}$ & $\begin{array}{c}2(3.2) \\
14(22.2) \\
12(19.0)\end{array}$ & 5.181 & 0.075 \\
\hline Tumor $(\mathrm{T})$ & $\begin{array}{c}\text { Tl }(\leq 3 \mathrm{~cm}) \\
\text { T2 }(3 \mathrm{~cm}<\mathrm{T} \leq 5 \mathrm{~cm}) \\
\text { T3 }(>5 \mathrm{~cm})\end{array}$ & $\begin{array}{l}17 \\
26 \\
20\end{array}$ & $\begin{array}{c}10(15.9) \\
7(11.1) \\
3(4.8)\end{array}$ & $\begin{array}{l}7(11.1) \\
19(30.2) \\
17(27.0)\end{array}$ & 8.620 & 0.013 & $\begin{array}{c}6(9.5) \\
14(22.2) \\
15(23.8)\end{array}$ & $\begin{array}{c}11(17.5) \\
12(19.0) \\
5(7.9)\end{array}$ & 5.920 & 0.052 \\
\hline Lymph & $\begin{array}{l}\text { No } \\
\text { Yes }\end{array}$ & $\begin{array}{l}36 \\
27\end{array}$ & $\begin{array}{c}14(22.2) \\
6(9.5)\end{array}$ & $\begin{array}{l}22(34.9) \\
21(33.3)\end{array}$ & 1.978 & 0.160 & $\begin{array}{l}22(34.9) \\
13(20.6)\end{array}$ & $\begin{array}{l}14(22.2) \\
14(22.2)\end{array}$ & 1.050 & 0.306 \\
\hline Postoperative radiotherapy & $\begin{array}{l}\text { No } \\
\text { Yes }\end{array}$ & $\begin{array}{l}27 \\
36\end{array}$ & $\begin{array}{c}8(12.7) \\
12(19.0)\end{array}$ & $\begin{array}{l}19(30.2) \\
24(38.1)\end{array}$ & 0.098 & 0.755 & $\begin{array}{l}17(27.0) \\
18(28.6)\end{array}$ & $\begin{array}{l}10(15.9) \\
18(28.6)\end{array}$ & 1.050 & 0.306 \\
\hline
\end{tabular}

Notes: Based on the principles of the AJCC (American Joint Committee on Cancer) and the UJCC (International Union Against Cancer) in I997, the criterion of newly revised TNM staging were adopted to clinical stage of lung cancer.

Table 2 The Correlation of TLR9 Expression in Cancer Tissues and Postoperative Survival

(A) The risk evaluation of TLR9, RUNX3 and cliniopathological factors in lung cancer by Logistic Regression Model

\begin{tabular}{|c|c|c|c|c|c|c|c|c|}
\hline & \multirow[t]{2}{*}{ B } & \multirow[t]{2}{*}{ SE } & \multirow[t]{2}{*}{ Wald } & \multirow[t]{2}{*}{$d f$} & \multirow[t]{2}{*}{ Sig. } & \multirow[t]{2}{*}{$\operatorname{Exp}(B)$} & \multicolumn{2}{|c|}{$95 \% \mathrm{Cl}$ for $\operatorname{EXP}(\mathrm{B})$} \\
\hline & & & & & & & Lower & Upper \\
\hline T stage & 0.999 & 0.493 & 4.103 & I & 0.043 & 2.716 & 1.033 & 7.143 \\
\hline TLR9 & 1.621 & 0.693 & 5.465 & 1 & 0.019 & 5.057 & 1.299 & 19.678 \\
\hline Constant & -1.630 & 0.921 & 3.137 & $\mathrm{I}$ & 0.077 & 0.196 & & \\
\hline
\end{tabular}

(B) The postoperative survival analysis on TLR9 expression in lung cancer

\begin{tabular}{|l|c|c|c|c|c|}
\hline \multirow{2}{*}{} & & \multicolumn{2}{|c|}{ PFS (Med time: mon) } & \multicolumn{2}{c|}{ OS (Med time: mon) } \\
\cline { 3 - 6 } & & Postoperation & Radiotherapy & Postoperation & Radiotherapy \\
\hline TLR9 & & & & 27.00 & 29.00 \\
& Negative & 18.00 & 16.50 & 34.12 & 0.030 \\
Wilcoxon statistic & Positive & 19.50 & 16.88 & 1.241 & 0.958 \\
Sig. & 0.014 & 0.010 & 0.265 & \\
\hline
\end{tabular}

Figure 3. This result implied that the patients with TLR9 signaling activation was a survival benefit from postoperative radiotherapy in $R U N X 3$ high expression. With Cox regression for PFS on lung cancer radiotherapy, the risk evaluation of tumor differentiation, $\mathrm{T}$ staging and $R U N X 3$ in equation in Table 3 was statistic significance, $P=0.026$, 0.055 and 0.001 , respectively. The relative risk was 2.109 , 1.861 and 0.178 with $95 \% \mathrm{CI}$ for $\operatorname{Exp}(\mathrm{B})(1.093-4.071)$, (0.987-3.509) and (0.067-0.475). The result illuminated that the high expression of $R U N X 3$ was helpful for 

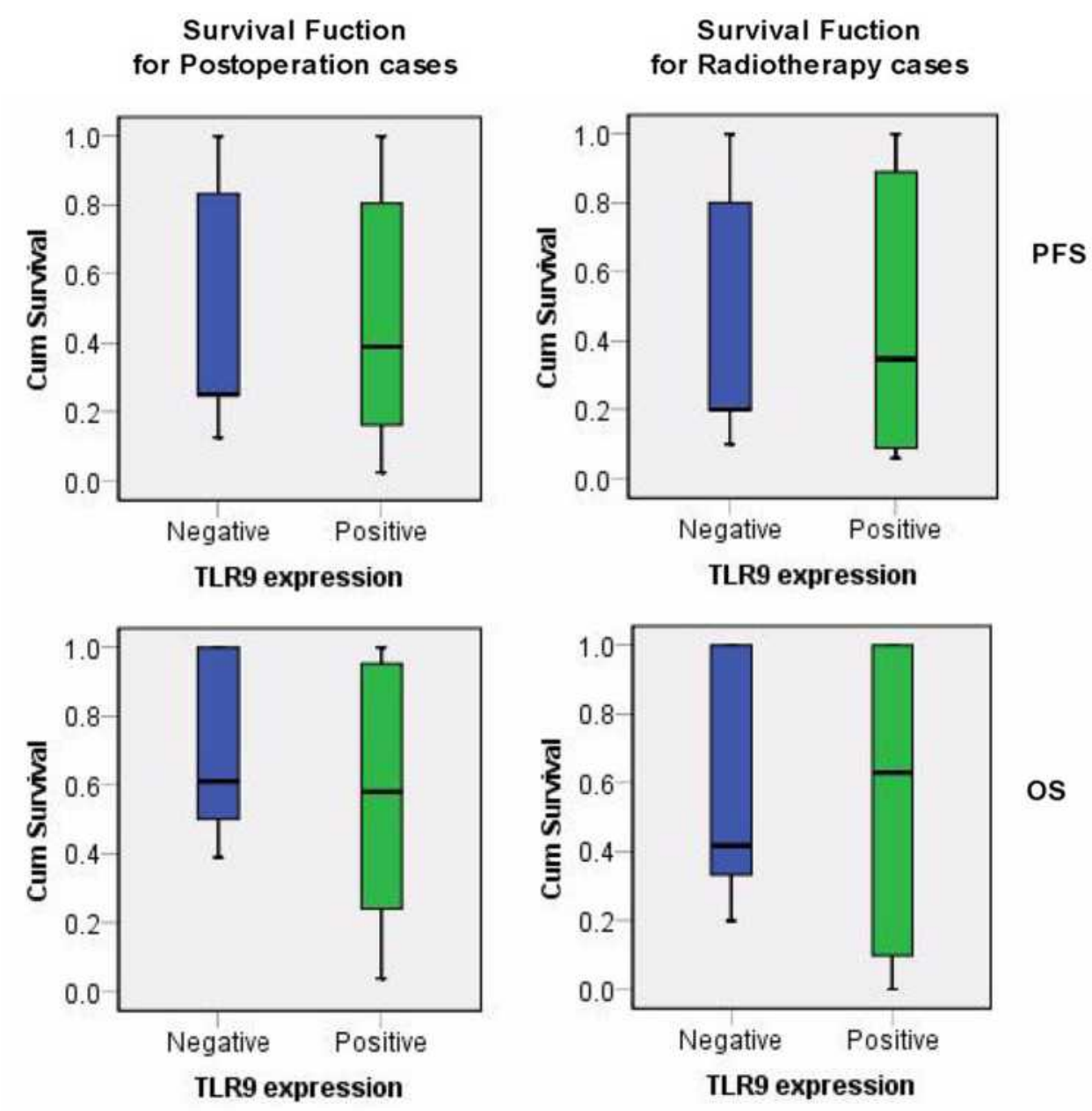

Figure 2 The survival function of lung cancer postoperation related TLR9 expression. X axis was identified for TLR9 status, Y axis indicated the cumulative survival of PFS and $O S$ on lung cancer postoperation and radiotherapy respectively.

Note: PFS and OS refer to progression-free survival and overall survival respectively.

postoperative radiotherapy survival in lung cancer. It was meaningful for upregulating $R U N X 3$ expression to improve radiotherapy outcome in lung cancer.

\section{RUNX3 Expression in Experimental Cells Before and After Radiotherapy}

In order to demonstrate the effect of RUNX3 in lung cancer radiotherapy, the levels of TLR 9 and $R U N X 3$ protein in experiment cells was detected by Western blotting (shown in Figure 4). Based on RUNX3 antibody instructions and double-band pattern, $R U N X 3-\mathrm{A}$ and $R U N X 3-\mathrm{B}$ standing for the band with larger and smaller molecular weight, respectively were adopted to data analysis in the study. The results displayed the levels of RUNX3 protein in 5 -Aza-CdR treatment cells was increased especially
$R U N X 3$-B before irradiation. Compared with A549 $9^{\text {high-TLR9 }}$ cells, RUNX3-B high expression in 5-AzaCdR treatment cells was significance, with the $t$ value $3.785, P<0.05$. The levels of $R U N X 3$ protein in cells postirradiation were decreased with no difference. TLR 9 expression in A549 $9^{\text {high-TLR9 }}$ and A549 cells was statistical significance, $t=4.081$ and $P<0.01$. It was the explanation for TLR9 signal activation in A549 cell exposure repeatedly.

\section{Cycle Distribution Related RUNX3 Upregulation in Lung Cancer Radiotherapy}

The distribution of the cell cycle in experiment was tested, shown in Figure 5A. Compared with the cell irradiation 
Table 3 The Effect of TLR9 and RUNX3 Expression on Postoperative Radiotherapy Survival of Lung Cancer

(A) The analysis of postoperative radiotherapy survival on TLR9 and RUNX3 expression

\begin{tabular}{|c|c|c|c|c|c|c|c|c|c|}
\hline & & \multirow{2}{*}{\multicolumn{2}{|c|}{$\begin{array}{c}\text { PFS (Med time: mon) } \\
\text { RUNX3 expression }\end{array}$}} & \multirow[t]{3}{*}{ Wilcoxon Statistic } & \multirow[t]{3}{*}{ Sig. } & \multirow{2}{*}{\multicolumn{2}{|c|}{$\begin{array}{c}\text { OS (Med time: mon) } \\
\text { RUNX3 expression }\end{array}$}} & \multirow[t]{3}{*}{ Wilcoxon Statistic } & \multirow[t]{3}{*}{ Sig. } \\
\hline & & & & & & & & & \\
\hline & & High & Low & & & High & Low & & \\
\hline \multirow[t]{3}{*}{ TLR9 } & & & & & & & & & \\
\hline & Negative & 45.00 & 15.00 & 1.905 & 0.168 & 59.63 & 23.25 & 4.224 & 0.040 \\
\hline & Positive & 21.00 & 12.00 & 6.097 & 0.014 & 34.72 & 24.00 & 6.521 & 0.011 \\
\hline
\end{tabular}

(B) The Cox proportional hazard regression of TLR9, RUNX3 and cliniopathological features for postoperative radiotherapy survival in lung cancer

\begin{tabular}{|l|c|c|c|c|c|c|c|c|}
\hline & B & S.E. & Wald & df & Sig. & Exp(B) & \multicolumn{2}{|c|}{$95 \%$ CI for EXP(B) } \\
\cline { 3 - 8 } & & & & & & & Lower & Upper \\
\hline Differentiation & 0.746 & 0.336 & 4.945 & 1 & 0.026 & 2.109 & 1.093 & 4.071 \\
T stage & 0.621 & 0.324 & 3.680 & 1 & 0.055 & 1.861 & 0.987 & 3.509 \\
RUNX3 & -1.724 & 0.500 & 11.907 & 1 & 0.001 & 0.178 & 0.067 & 0.475 \\
\hline
\end{tabular}

only, the cell proportion in $\mathrm{G} 2 / \mathrm{M}$ and $\mathrm{G} 1 / \mathrm{G} 0$ in A549 $9^{\text {high-TLR9 }}+5$-Aza-CdR/IR group was $44.8 \pm 1.76$ and $45.73 \pm 1.67$, respectively with the $t$ values 14.15 and 13.52, $P<0.001$ equally. There was no change in cell distribution in 5-Aza-CdR treatment and the irradiation only group. The fewer G2/M cells and more $\mathrm{G} 1 / \mathrm{G} 0$ cells in the $\mathrm{A} 549^{\text {high- } T L R 9}+\mathrm{CQ} / \mathrm{IR}$ group than that in A549 ${ }^{\text {high-TLR9 }} /$ IR group were examined. Furthermore we examined 5-Aza-CdR induced cells blocking in G2/M with maximization at irradiation $24 \mathrm{~h}$ and maintained for $36 \mathrm{~h}$ and $48 \mathrm{~h}$ after radiotherapy, as shown in Figure 5B. The distribution of $\mathrm{S}$ cells in chloroquine combining irradiation was more than in the A549 $9^{\text {high-TLR9 }} /$ IR group at 12 h with the $t$ values 11.04 and $P<0.001$. Meanwhile we saw fewer G2/M cells and many more G1/G0 cells in A549 $9^{\text {high-TLR9 }}+\mathrm{CQ} / \mathrm{IR}$ group than the irradiated cells alone.

\section{Discussion}

Radiotherapy is a common clinical treatment for lung cancer patients. TLRO is a transmembrane protein. It is activated by binding unmethylated $\mathrm{CpG}$ sequences in DNA molecules to TIR domain. ${ }^{22,23}$ The researchers have demonstrated that irradiation leads to DNA damage and cells debris and proteins associated with hypoxia and necrosis activates TLR 9 signal cascades by endogenous DAMPs, which promotes downstream pro-inflammatory cytokines synthesis. The result contributes to the alternative tumor microenvironment and host immunity and influences clinical treatment outcomes. ${ }^{24-26}$ RUNX3 encodes a heterodimer comprised of a Runt domain containing $\alpha$ subunit and a DNA-binding $\beta$ subunit. ${ }^{27,28}$ It is reported that the high expression of $R U N X 3$ in CD8+ $\mathrm{T}$ cells is essential to suppress transcription of CD4 silencer and regulates the expression of CD8+ T-cell specific genes. ${ }^{29-31}$ The differentiation of Th1 cells is determined by transcription factor T-bet and the induction of RUNX3 expression. The interaction between transcription factor T-bet and RUNX3 causes large production of IFN- $\gamma$ and the silence of IL4 gene. ${ }^{15,32}$ However, the low expression of $R U N X 3$ due to DNA methylation at $\mathrm{CpG}$ site has also been demonstrated in various tumors. ${ }^{33}$ For these reasons, the aim of this study was to investigate whether the high expression of $R U N X 3$ influences irradiation immune responses related $T L R 9$ signal activation and enhanced radiotherapy effects.

We characterized the expression of TLR 9 in tumor tissues and $R U N X 3$ in paracarcinoma tissues and explored the relationship with postoperative radiotherapy survival in lung cancer. The result present that TLR 9 expression and tumor $\mathrm{T}$ staging among clinicopathologic features were the variables of relative risk 


\section{Survival Fuction on negative TLR9 expression}

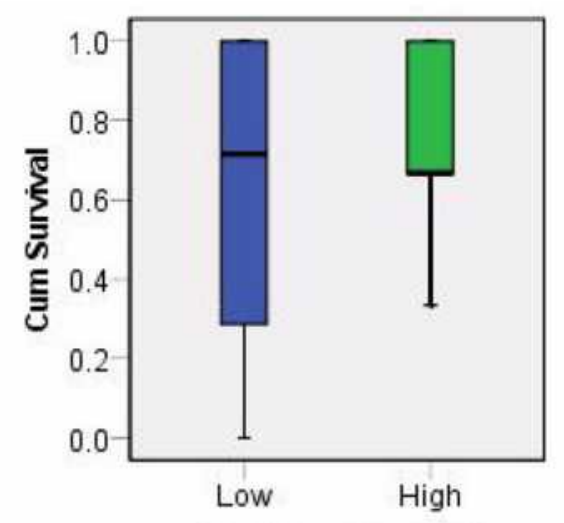

RUNX3 expression

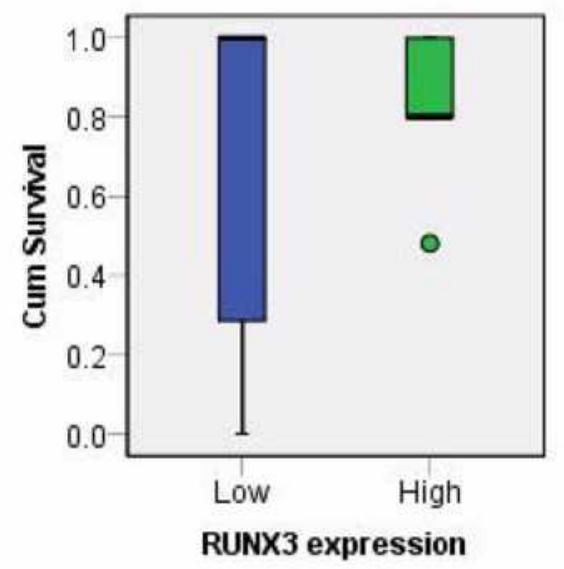

\section{Survival Fuction on positive TLR9 expression}

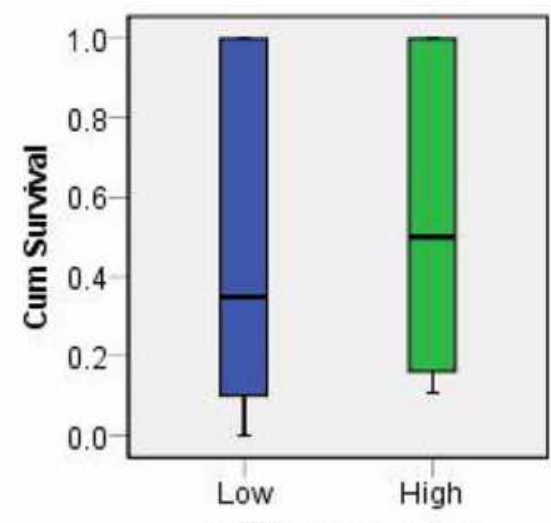

PFS

RUNX3 expression

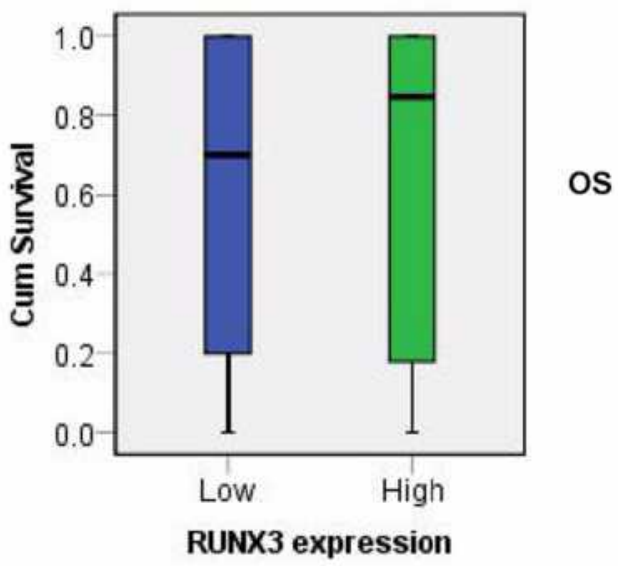

Figure 3 The survival function of lung cancer radiotherapy related TLR9 and RUNX3 expression. X axis was identified for RUNX3 status, Y axis indicated the cumulative survival of PFS and OS on lung cancer radiotherapy with negative and positive TLR9 expression.

Note: PFS and OS refer to progression-free survival and overall survival respectively.

in postoperative survival of lung cancer with statistic value 5.057 and 2.716 , respectively. It suggested that TLR9 signal activation was the disadvantage of postoperative survival in lung cancer. And we observe no difference in PFS and OS of postoperative or radiotherapy survival in lung cancer. However patients with $R U N X 3$ high expression had the better PFS and OS in postoperative radiotherapy, either positive or negative TLR9 expression. This result confirmed that RUNX3 expression in paracarcinoma tissues of lung cancer mediated irradiation effects and impact the survival on postoperative radiotherapy. The analysis of Cox regression on PFS in lung cancer radiotherapy revealed that the relative risk on tumor differentiation, tumor
T staging, and $R U N X 3$ was $2.109,1.861$, and 0.178 , respectively. It was certain that the high expression of $R U N X 3$ was significant to improve radiotherapy outcomes associated with TLR 9 activation.

To test the effect of RUNX3 on lung cancer radiotherapy related TLR 9 signal activation, we introduced 5-Aza-CdR and lung cancer A549 cell was exposed repeatedly and detected the expression of TLR 9 and $R U N X 3$ in experimental cells. The increasing levels of $T L R 9$ protein obviously in A549high-TLR9 cells was observed. We also examined the levels of RUNX3 protein especially $R U N X 3-\mathrm{B}$ in 5 -Aza-CdR treatment cells was higher than in A549 ${ }^{\text {high-TLR9 }}$ cells. Furthermore we found that the G2/M cells in 5-Aza-CdR combining 


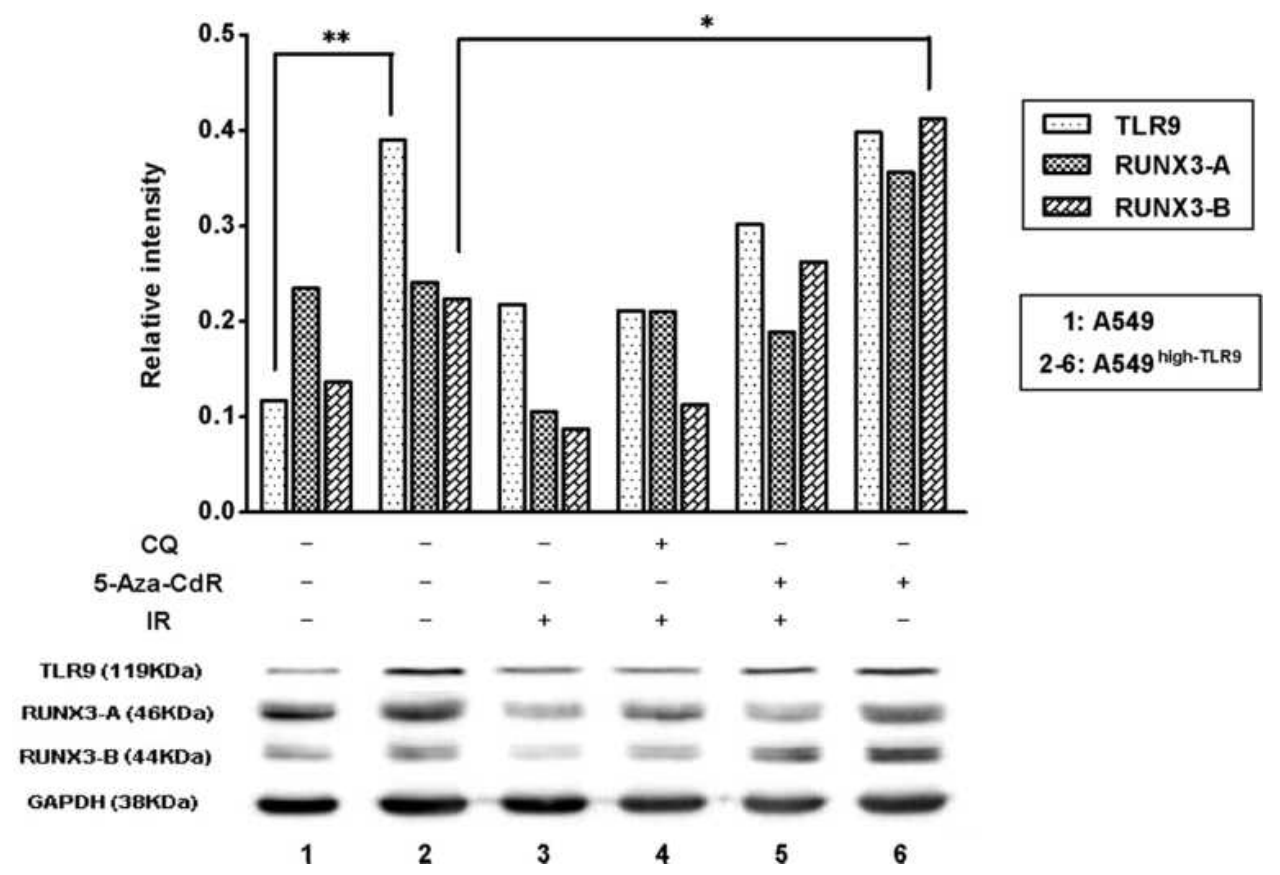

Figure 4 RUNX3 and TLR9 expression in cells before and after radiotherapy. The levels of RUNX3 and TLR9 protein in experimental cells were detected by Western blotting. RUNX3-A and RUNX3-B standard for the larger and smaller molecular weight band separately. The levels of TLR9 protein in the A549high-TLR9 cell was significantly more than in the $A 549$ cell, $t=4.08 \mathrm{I}$ and $P<0.0 \mathrm{I}$. It indicated that TLR9 signaling activated in $A 549$ cells exposure repeatedly. The result displayed that $R U N X 3$ protein especially RUNX3-B was increased in 5-Aza-CdR treatment cells. In comparison with the A549high-TLR9 cell, the increasing levels of RUNX3-B protein was significant, with the $t$ value 3.785 and $P<0.05$. The decreased levels of RUNX3 protein in cells after irradiation was observed with no difference.

Notes: $*_{t}=3.785, P<0.05 ; * * t=4.081, P<0.01$.

Abbreviations: IR, irradiation; A549 ${ }^{\text {high-TLR9 }}$ cell, A549 cell with TLR9 signal activation; 5-Aza-CdR, 5-Aza-2'-deoxycytidine; CQ, chloroquine.

radiotherapy was sevenfold to the 5 -Aza-CdR treatment group and twofold to the cell irradiated solely, respectively. It was maximized at irradiation $24 \mathrm{~h}$ and kept the irradiation advantage until $36 \mathrm{~h}$ and $48 \mathrm{~h}$. It is known that the $\mathrm{G} 2 / \mathrm{M}$ cells has the most sensitivity to irradiation. It was remarkable that 5 -Aza-CdR treatment combined radiotherapy made more cells block in the $\mathrm{G} 2 / \mathrm{M}$ phase and enhanced irradiation effect. In contrast, we observed the $\mathrm{S}$ cells prolonged in chloroquine combining radiotherapy, which was insensitive to X-rays. It suggested that only inhibiting TLR 9 signaling was unable to improve the radiation resistance related TLR 9 signaling activation. And this result also conformed to our first clinical investigation. Considering the higher proportion of $\mathrm{G} 2 / \mathrm{M}$ cells in 5 -Aza-CdR adjuvant radiotherapy we thought that
$R U N X 3$ expression upregulation played a key role in this process. It showed the radiosensitization of 5-Aza$\mathrm{CdR}$ in lung cancer with TLR9 signaling activation by upregulating $R U N X 3$ expression. We concluded that it was necessary to raise $R U N X 3$ expression to promote the irradiation effect in lung cancer with TLR9 signaling activation.

\section{Conclusion}

In summary, TLR 9 signaling activation involved in tumor progression and influenced the postoperative radiotherapy survival in lung cancer. It was notable that the increasing levels of RUNX3 protein could contribute to reverse radioresistance in this process and improve the survival related lung cancer radiotherapy. Of course, 5-Aza-CdR was considerable. 

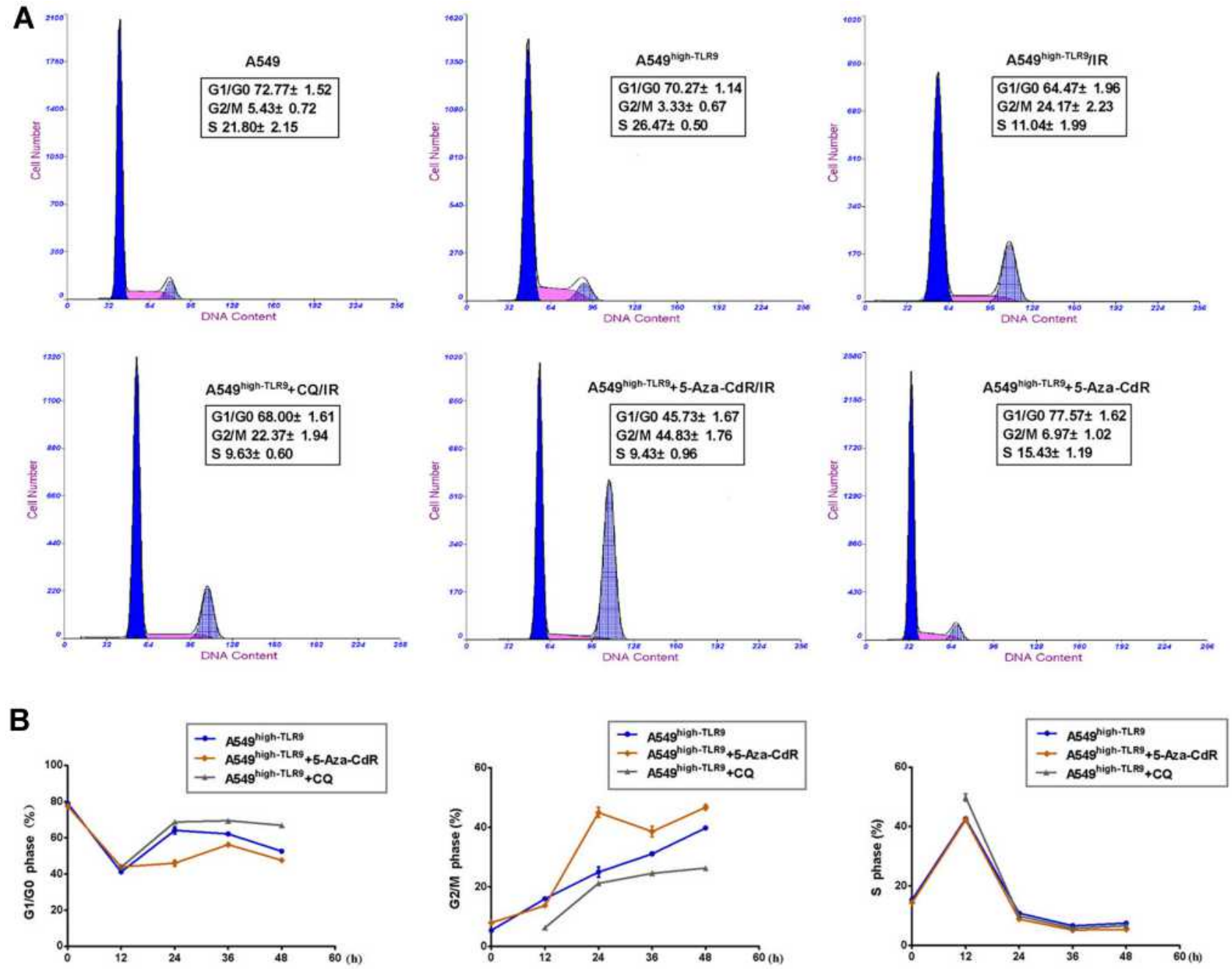

Figure 5 Comparison of cell distribution on experimental cells before and after radiotherapy. The cycle distribution in experimental cells before and after radiotherapy (A). The proportion of $\mathrm{G} 2 / \mathrm{M}$ cells in 5 -Aza-CdR treatment at irradiation $24 \mathrm{~h}$ was $44.83 \pm 1.76$, twice that of solely irradiated cells significantly, $t=15.52$ and $P<0.001$. It maintained for irradiation $36 \mathrm{~h}$ and $48 \mathrm{~h}$ (B). The GI/G0 cells in 5-Aza-CdR adjuvant radiotherapy remained low for irradiation $48 \mathrm{~h}$. The cells ratio in $\mathrm{S}$ phase in chloroquine combining radiotherapy at irradiation $12 \mathrm{~h}$ was $15.43 \pm 1.19$, which was significantly more than the solely irradiated cells, $P<0.00 \mathrm{I}$. The result was that after irradiation more cells kept in G2/M phase in 5-Aza-CdR treatment group as well more cells in $S$ phase in chloroquine combining radiotherapy.

\section{Acknowledgment}

The experimental design and data analysis were directed by Dr Qiao. Zhuangxibing took part in the medical records collection in this study, Yuansujun participated in the experimental process. The authors are grateful for their hard work.

\section{Disclosure}

The authors report no competing interests in this work.

\section{References}

1. Chen K, Huang J, Gong W, Iribarren P, Dunlop NM, Wang JM. Toll-like receptors in inflmmation, infection and cancer. Int Immunopharmacol. 2007;7:1271-1285. doi:10.1016/j.intimp.2007.05.016
2. Droemann D, Albrecht D, Gerdes J, et al. Human lung cancer cells express functionally active Toll-like receptor 9. Respir Res. 2005;6:1. doi:10.1186/1465-9921-6-1

3. Merrell MA, Ilvesaro JM, Lehtonen N, et al. Toll-like receptor 9 agonists promote cellular invasion by increasing matrix metalloproteinase activity. Mol Cancer Res. 2006;4:437-447. doi:10.1158/15417786.MCR-06-0007

4. Takala H, Kauppila JH, Soini Y, et al. Toll-like receptor 9 is a novel biomarker for esophageal squamous cell dysplasia and squamous cell carcinoma progression. $J$ Innate Immun. 2011;3:631-638. doi: $10.1159 / 000329115$

5. Ren T, Xu L, Jiao S, et al. TLR9 signaling promotes tumor progression of human lung cancer cell In vivo. Pathol Oncol Res. 2009;15 (4):623-630. doi:10.1007/s12253-009-9162-0

6. Xu L, Wang C, Wen Z, et al. CpG oligodeoxynucleotides enhance the efficacy of adoptive cell transfer using tumor infiltrating lymphocytes by modifying the Th1 polarization and local infiltration of Th17 cells. Clin Dev Immunol. 2010;2010:410893. doi:10.1155/2010/410893 
7. Kundu SD, Lee C, Billips BK, et al. The toll-like receptor pathway: a novel mechanism of infection-induced carcinogenesis of prostate epithelial cells. Prostate. 2008;68(2):223-229. doi:10.1002/ pros. 20710

8. Väisänen MR, Väisänen T, Jukkola-Vuorinen A, et al. Expression of toll-like receptor-9 is increased in poorly differentiated prostate tumors. Prostate. 2010;70(8):817-824. doi:10.1002/pros.21115

9. Kauppila JH, Takala H, Selander KS, Lehenkari PP, Saarnio J, Karttunen TJ. Increased Toll-like receptor 9 expression indicates adverse prognosis in oesophageal adenocarcinoma. Histopathology. 2011;59(4):643-649. doi:10.1111/j.1365-2559.2011.03991.x

10. Wang C, Cao S, Yan Y, et al. TLR9 expression in glioma tissues correlated to glioma progression and the prognosis of GBM patients. BMC Cancer. 2010;10:415. doi:10.1186/1471-2407-10-415

11. Bae SC, Choi JK. Tumor suppressor activity of RUNX3. Oncogene. 2004;23(24):4336-4340. doi:10.1038/sj.onc. 1207286

12. Bangsow C, Rubins N, Glusman G, et al. The RUNX3 gene-sequence, structure and regulated expression. Gene. 2001;279 (2):221-232. doi:10.1016/S0378-1119(01)00760-0

13. Milner JJ, Toma C, Yu B, et al. Runx3 programs $\mathrm{CD}^{+} \mathrm{T}$ cell residency in non-lymphoid tissues and tumors. Nature. 2017;552 (7684):253-257. doi:10.1038/nature24993

14. Mami-Chouaib F, Blanc C, Corgnac S, et al. Resident memory $\mathrm{T}$ cells, critical components in tumor immunology. $J$ ImmunoTher Cancer. 2018;6:87. doi:10.1186/s40425-018-0399-6

15. Djuretic IM, Levanon D, Negreanu V, Groner Y, Rao A, Ansel KM. Transcription factors T-bet and Runx3 cooperate to activate $I F N-\gamma$ and silence IL4 in T helper type 1 cells. Nat Immunol. 2006;8 (7):145-153

16. Torres-Roca JF, Eschrich S, Zhao H, et al. Prediction of radiation sensitivity using a gene expression classifier. Cancer Res. 2005;65:7169-7176. doi:10.1158/0008-5472.CAN-05-0656

17. Esteller M. Epigenetic gene silencing in cancer: the DNA hypermethylome. Hum Mol Genet. 2007;16(1):R50-R59. doi: $10.1093 / \mathrm{hmg} / \mathrm{ddm} 018$

18. Kim HJ, Kim JH, Chie EK, et al. DNMT (DNA methyltransferase) inhibitors radiosensitize human cancer cells by suppressing DNA repair activity. Radiat Oncol. 2012;7(1):39. doi:10.1186/1748-717X7-39

19. Valdez BC, Li Y, Murray D, Corn P, Champlin RE, Andersson BS. 5-Aza-2'-deoxycytidine sensitizes busulfan-resistant myeloid leukemia cells by regulating expression of genes involved in cell cycle checkpoint and apoptosis. Leuk Res. 2010;34(3):364-372. doi:10.1016/j.leukres.2009.08.014

20. Oing C, Verem I, Mansour WY, Bokemeyer C, Dyshlovoy S, Honecker F. 5-Azacitidine exerts prolonged pro-apoptotic effects and overcomes cisplatin-resistance in non-seminomatous germ cell tumor cells. Int J of Mol Sci. 2019;20:21. doi:10.3390/ijms20010021
21. Yan L, Xu G, Qiao T, Chen W, Yuan S, Li X. CpG ODN 7909 increases radiation sensitivity of radiation-resistant human lung adenocarcinoma cell line by overexpression of toll-like receptor 9 . Cancer Biother Radiopharm. 2013;28(7):559-564. doi:10.1089/ cbr.2012.1450

22. Takeda K, Kaisho T, Akira S. Toll-like receptors. Annu Rev Immunol. 2003;21:335-376. doi:10.1146/annurev.immunol.21.120601.141126

23. Hoshino K, Kaisho T, Lwabe T, Takeuchi O, Akira S. Differential involvement of IFN-beta in Toll-like receptor stimulated dendritic cell activation. Int Immunol. 2002;14(10):1225-1231. doi:10.1093/ intimm/dxf089

24. Johnson GB, Brunn GJ, Tang AH, Platt JL. Evolutionary clues to the functions of the Toll-like family as surveillance receptors. Trends Immunol. 2003;24(1):19-24.

25. Peter M, Bode K, Lipford GB, Eberle F, Heeg K, Dalpke AH. Characterization of suppressive oligodeoxynucleotides that inhibit Toll-like receptor 9 mediated activation of innate immunity. Immunology. 2008;123(1):118-128. doi:10.1111/j.13652567.2007.02718.x

26. Serafini P, De Santo C, Marigo I, et al. Derangement of immune responces by myeloid suppressor cells. Cancer Immunol Lmmunother. 2004;53(2):64-72. doi:10.1007/s00262-003-0443-2

27. Yano T, Ito K, Fukamachi H, et al. The RUNX3 tumor suppressor upregulates Bim in gastric epithelial cells undergoing transfoming growth factor $\beta$-induced apoptosis. $\mathrm{Mol}$ Cell Biol. 2006;26:4474-4488. doi:10.1128/MCB.01926-05

28. Durst KL, Hiebert SW. Role of RUNX family members in transcriptional repression and gene silencing. Oncogene. 2004;23 (24):4220-4224. doi:10.1038/sj.onc. 1207122

29. Ohno S, Sato T, Kohu K, et al. Runx proteins are involved in regulation of $\mathrm{CD} 122$, Ly49 family and IFN- $\gamma$ expression during NK cell differentiation. Int Immunol. 2008;20(1):71-79. doi:10.1093/ intimm/dxm 120

30. Taniuchi I, Littman DR. Epigenetic gene silencing by Runx proteins. Oncogene. 2004;23(24):4341-4345. doi:10.1038/sj.onc.1207671

31. Sato T, Ohno S, Hayashi T, et al. Dual functions of Runx proteins for reactivating $\mathrm{CD} 8$ and silencing $\mathrm{CD} 4$ at the commitment process into CD8 thymocytes. Immunity. 2005;22(3):317-328. doi:10.1016/j. immuni.2005.01.012

32. Schulz EG, Mariani L, Radbruch A, Höfer T. Sequential polarization and imprinting of type $1 \mathrm{~T}$ helper lymphocytes by interferon- $\gamma$ and interleukin-12. Immunity. 2009;30(5):673-683. doi:10.1016/j. immuni.2009.03.013

33. Wolff EM, Liang G, Cortez CC, et al. RUNX3 methylation reveals that bladder tumors are older in patients with a history of smoking. Cancer Res. 2008;68(15):6208-6214. doi:10.1158/0008-5472.CAN07-6616
Cancer Management and Research

\section{Publish your work in this journal}

Cancer Management and Research is an international, peer-reviewed open access journal focusing on cancer research and the optimal use of preventative and integrated treatment interventions to achieve improved outcomes, enhanced survival and quality of life for the cancer patient.
The manuscript management system is completely online and includes a very quick and fair peer-review system, which is all easy to use. Visit http://www.dovepress.com/testimonials.php to read real quotes from published authors. 